\title{
BMJ Open Association between 7-day serum $\beta$-hCG levels after frozen-thawed embryo transfer and pregnancy outcomes: a single-centre retrospective study from China
}

\author{
Lihua Yuan, ${ }^{1}$ Lingyu Yu, ${ }^{1}$ Zhengao Sun (D , ${ }^{2}$ Jingyan Song, ${ }^{3}$ Jimei Xiao, \\ Huaying Jiang, ${ }^{1}$ Yuanhong $\mathrm{Sa}^{1}$
}

To cite: Yuan L, Yu L, Sun Z, et al. Association between 7-day serum $\beta$-hCG levels after frozen-thawed embryo transfer and pregnancy outcomes: a single-centre retrospective study from China. BMJ Open 2020;10:e035332. doi:10.1136/ bmjopen-2019-035332

- Prepublication history for this paper is available online. To view these files, please visit the journal online (http://dx.doi. org/10.1136/bmjopen-2019035332).

ZS and JS contributed equally.

LYuan and LYu are joint first authors.

Received 17 November 2019 Revised 04 June 2020 Accepted 16 July 2020

Check for updates

(C) Author(s) (or their employer(s)) 2020. Re-use permitted under CC BY-NC. No commercial re-use. See rights and permissions. Published by BMJ.

For numbered affiliations see end of article.

Correspondence to Professor Zhengao Sun; sunzhenga077@126.com

\section{ABSTRACT}

Objective Early monitoring of plasma human chorionic gonadotropin ( $\beta$-hCG) level is vital in predicting pregnancy outcome. This study investigated the predictive value of serum $\beta$-hCG level on the seventh day after frozenthawed embryo transfer (FET) for ongoing pregnancy (OP) and adverse pregnancy (AP).

Design Retrospective study.

Setting The Reproductive and Genetic Center of the Affiliated Hospital of Shandong University of Traditional Chinese Medicine, China.

Participants 1061 pregnant women who underwent FET between January 2014 and January 2017.

Primary and secondary outcome measures Pregnancy outcome.

Results Serum $\beta$-hCG levels on the seventh day after FET were higher in the single OP group compared with the biochemical pregnancy group $(p<0.001)$. Besides, the serum $\beta$-hCG cut-off level at $4.34 \mathrm{mlU} / \mathrm{mL}$ on the seventh day showed high predictive value (area under the curve $(A U C)=0.852)$. Serum $\beta$-hCG levels on the seventh day after FET were higher in the twin OP group compared with the single OP group $(\mathrm{p}<0.001)$. Also, the serum $\beta$-hCG cutoff level at $17.95 \mathrm{mlU} / \mathrm{mL}$ on the seventh day showed high predictive value $(A U C=0.903)$. Serum $\beta$-hCG levels on the seventh day after FET were lower in the ectopic pregnancy group compared with the single OP group $(p<0.001)$ whereas, serum $\beta$-hCG cut-off level at $4.53 \mathrm{mlU} / \mathrm{mL}$ on the seventh day exhibited a high predictive value $(A U C=0.860)$. Further, the serum $\beta$-hCG levels on the seventh day after FET were lower in the single early spontaneous abortion group compared with the single OP group $(p<0.001)$ while the serum $\beta$-hCG cut-off level at $5.34 \mathrm{mlU} / \mathrm{mL}$ on the seventh day exhibited high predictive value $(A U C=0.738)$. Conclusion Serum $\beta$-hCG on the seventh day after FET has good clinical significance for the prediction of $O P$ and $A P$.

\section{INTRODUCTION}

Assisted reproductive technology (ART) has recently been considered an effective strategy to treat prolonged cases of infertility and up to

\section{Strengths and limitations of this study}

- First study evaluating the predictive value of serum plasma human chorionic gonadotropin ( $\beta$-hCG) for ongoing pregnancy (OP) and adverse pregnancy (AP) on day 7 after frozen-thawed embryo transfer (FET).

- Serum $\beta$-hCG on day 7 after FET has good clinical significance for the prediction of $\mathrm{OP}$ and $\mathrm{AP}$.

- The results are only generalisable to patients with fallopian tube factor infertility undergoing FET.

- A retrospective study is prone to selection bias.

A small single-centre observational study.

$22 \%$ of bad pregnancy outcomes. ${ }^{1}$ Predicting pregnancy outcomes at early stages is critical in determining the patients' mental state and devising clinical decisions in health practice.

Human chorionic gonadotropin (hCG) is secreted by syncytiotrophoblasts as a glycoprotein hormone within the placenta. It is composed of $\alpha$ and $\beta$ subunits. $\beta$-hCG is the first observable trophoblast proliferation signal in the maternal blood after embryo implantation. Therefore, the presence of $\beta$-hCG in the maternal serum can be used to detect early pregnancy of up to 6-7 days after fertilisation. ${ }^{2}$ Moreover, serum $\beta$-hCG quantification has been applied to predict pregnancy outcomes since the 1960s. Several studies have confirmed that serum $\beta$-hCG is a reliable index for predicting early pregnancies at 12-18 days post-transplantation (dpt). The risk of adverse pregnancy (AP) outcomes such as ectopic pregnancy (EP), biochemical pregnancy (BP) and spontaneous abortion (SA) is greater in women undergoing ART compared with natural pregnancy. ${ }^{34}$

Many studies have reported that serum $\beta$-hCG efficiently predict pregnancy outcome. A study by Lawler et al found that serum 
$\beta$-hCG $>80 \mathrm{mIU} / \mathrm{mL}$ could predict an ongoing pregnancy (OP) on the 12th day after embryo transfer (ET). Moreover, they reported that a cut-off value of $86.8 \mathrm{mIU} / \mathrm{mL}$ could predict clinical pregnancy. ${ }^{5}{ }^{6}$ Therefore, it was concluded that serum $\beta$-hCG level at $>500 \mathrm{mIU} / \mathrm{mL}$ on the 16th day after ET is associated with a higher rate of OP. Moreover, Løssl $e t a l^{7}$ reported that serum $\beta$-hCG on the day of ET was significantly useful in predicting clinical pregnancy than OP. However, different studies report different optimum $\beta$-hCG threshold values for predicting pregnancy outcome. This may be attributed to differences in study designs, for example, blood sampling time and methods used in measuring serum $\beta$-hCG. Serum $\beta$-hCG is routinely measured in most reproductive centres at 14 dpt. However, we routinely measured serum $\beta$-hCG in our centre at $7 \mathrm{dpt}$ to alleviate the psychological tension and anxiety of patients and to predict the pregnancy outcome at early stages. Therefore, the present study evaluated the predictive value of serum $\beta$-hCG for OP and AP on the seventh day after FET.

\section{METHODS}

\section{Research objective}

A total of 2582 patients underwent in vitro fertilisation (IVF) and frozen-thawed embryo transfer (FET) at the Reproductive and Genetic Center of the Affiliated Hospital of Shandong University of Traditional Chinese
Medicine from January 2014 to January 2017. Notably, 1061 patients were included for analysis after having met the following inclusion and exclusion criteria. The inclusion criteria included: (1) age <38 years; (2) body mass index (BMI) between 18.5 and 25; (3) complete follow-up records until the end of delivery; (4) infertility caused by the fallopian tube factor; (5) have four or more available embryos and the transplanted embryos get a score of 6 or greater following the Istanbul Consensus but without preimplantation genetic screening/preimplantation genetic diagnosis; (6) transplant two embryos per cycle. The exclusion criteria included: (1) non-pregnancy; (2) abnormal fetal development on colour Doppler ultrasound or SA during the second pregnancy trimester; (3) luteal support with exogenous $\beta$-hCG after transplantation; (4) hydrosalpinx; (5) severe oligozoospermia or asthenospermia of the male partner; (6) a history of recurrent abortion. All patients provided informed consent before they were enrolled in the IVF-ET cycle. The 1061 patients were assigned into different groups as follows: Single OP group (515), twin OP group (238), EP group (55), single early SA group (167), BP group (86) based on the pregnancy outcome (figure 1).

\section{Patient and public involvement}

This study was designed without patient participation; and they were not invited to contribute to the study design and to develop patient-relevant outcomes or interpret the

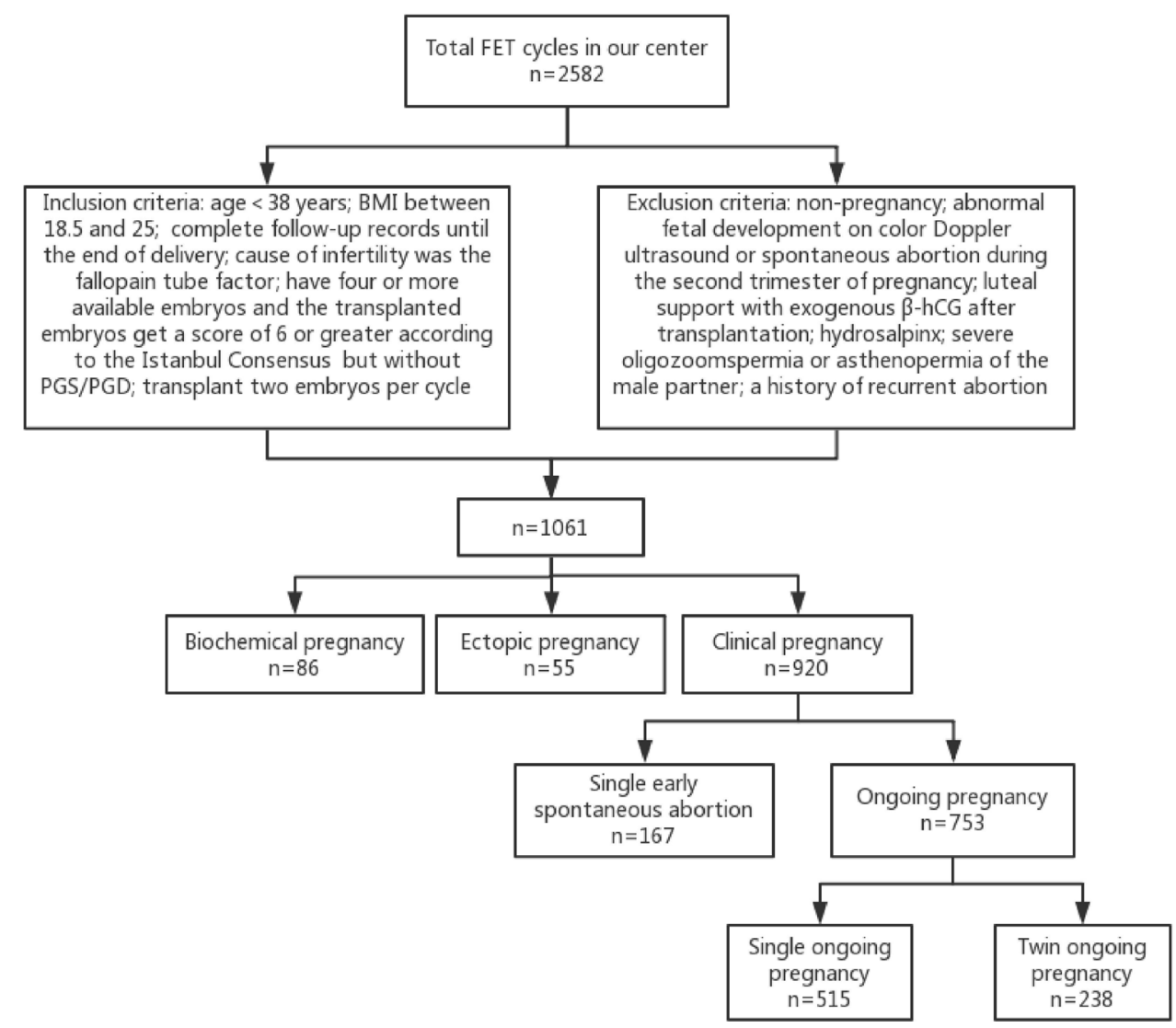

Figure 1 Flow chart of case selection. BMI, body mass index; $\beta$-hCG, human chorionic gonadotropin; FET, frozen-thawed embryo transfer; PGD, preimplantation genetic diagnosis; PGS, preimplantation genetic screening. 
results. Also, patients did not contribute to the writing or editing of this document for readability or accuracy.

\section{Assisted pregnancy method}

The replacement cycle was adopted to prepare the endometrium at our centre. The study participants were administered with progynova (four tablets per day) for 5 days, starting 2-4 days after the first day of the last menstrual cycle. Progesterone was administered when the endometrial thickness was $8 \mathrm{~mm}$ to induce the transformation of the endometrium to the secretory phase. Thereafter, the patient was prepared for FET. We routinely provided 14 days of luteal support after FET irrespective of pregnancy. For patients with OP, progynova and progesterone were continued for 10 weeks of gestation, and after confirming the presence of the fetal heart, the dosage was gradually reduced.

\section{Measurement of serum $\beta$-hCG}

At 7 and $14 \mathrm{dpt}$, venous blood was collected at 08:00-09:00 and centrifuged. $\beta$-hCG was measured from the collected serum via chemiluminescence.

\section{Grouping criteria for pregnancy outcomes}

BP refers to serum $\beta$-hCG $>5 \mathrm{mIU} / \mathrm{mL}$ after $\mathrm{FET}$ but with no gestational sac. Ultrasound examinations were performed on the 35th day after FET to detect the fetal heartbeat, which was defined as a clinical pregnancy. The pregnancy outcome was classified as a normal pregnancy or AP. Further, normal pregnancy was classified as either single or twin OP. The single OP refers to a single pregnancy with normal fetal development verified through obstetrical and ultrasound examination on or after the 12th gestational week. Twin OP refers to twin pregnancy exhibiting normal fetal development, which was verified through obstetrical and ultrasound examination on or after the 12th gestational week. AP included EP, BP and single SA. EP refers to the presence of an extrauterine mass but without a gestational sac in the uterus. Early SA refers to natural SA before the 12th gestational week.

\section{Statistical analysis}

IBM SPSS Statistics for Windows, V.22.0 (IBM Corporation, Armonk, New York, USA) was used to analyse all the data. Continuous quantitative data were first analysed using the Shapiro-Wilk normality test. Data showing normal distribution were presented as mean $\pm \mathrm{SD}(\bar{x} \pm s)$ and compared using one-way analysis of variance. Besides, data without normal distribution were presented as the median and IQR $\left(M\left(Q_{1}, Q_{3}\right)\right)$. The significant differences among the multiple groups were analysed using the Kruskal-Wallis $\mathrm{H}$ test. The serum $\beta$-hCG levels at 7 dpt were analysed using receiver operating characteristic (ROC) curves to differentiate pregnancy conditions. All tests were two-sided. A $p$ value $<0.05$ was considered statistically significant.

The statistical significance of the ROC area under the curve (AUC) was classified by Medcalc15 as follows: AUC $<0.5$ indicated no predictive value, $0.5 \leq$ AUC $<0.7$ indicated a low predictive value, $0.7 \leq \mathrm{AUC}<0.9$ indicated a moderate predictive value and $0.9 \leq \mathrm{AUC}<1$ indicated a high predictive value.

\section{RESULTS}

Of 1061 pregnancy patients, there were 515 cases of the single OP, 238 of twin OP, 55 of EP, 167 of single early SA and 86 of BP. Notably, we observed no significant differences in the factors including age, duration of infertility, BMI, levels of basal follicle-stimulating hormone, basal luteinising hormone, basal estradiol and endometrium thickness among groups on the day of ET ( $p>0.05$; table 1).

The serum $\beta$-hCG levels were compared among all groups on the seventh day after FET. We found significantly higher serum $\beta$-hCG levels in the twin OP group compared with the single OP group $(\mathrm{p}<0.05)$ (table 2$)$. Of note, serum $\beta$-hCG levels greater than $17.95 \mathrm{U} / \mathrm{L}$ were associated with a higher probability of multiple pregnancy $(\mathrm{AUC}=0.903, \quad$ sensitivity $=81.93 \%, \quad$ specificity $=87.77 \%)$

Table 1 Comparison of age, duration of infertility, BMI, bFSH, bLH, bE2 and endometrium thickness on FET day among groups $(\bar{x} \pm s)$

\begin{tabular}{|c|c|c|c|c|c|c|c|c|}
\hline Group & $\mathbf{n}$ & $\begin{array}{l}\text { Age } \\
\text { (years) }\end{array}$ & $\begin{array}{l}\text { Infertility } \\
\text { (years) }\end{array}$ & $\begin{array}{l}\text { BMI } \\
\left(\mathrm{kg} / \mathrm{m}^{2}\right)\end{array}$ & $\begin{array}{l}\text { bFSH } \\
\text { (U/L) }\end{array}$ & $\begin{array}{l}\text { bLH } \\
\text { (U/L) }\end{array}$ & $\begin{array}{l}\text { bE2 } \\
\text { (pg/mL) }\end{array}$ & $\begin{array}{l}\text { Endometrial } \\
\text { thickness on } \\
\text { FET day (mm) }\end{array}$ \\
\hline Single OP & 515 & $30.03 \pm 2.91$ & $3.36 \pm 2.22$ & $21.71 \pm 1.90$ & $6.18 \pm 1.89$ & $5.58 \pm 2.16$ & $41.84 \pm 16.74$ & $10.98 \pm 1.77$ \\
\hline Twin OP & 238 & $29.84 \pm 2.98$ & $3.22 \pm 1.85$ & $21.93 \pm 1.83$ & $6.26 \pm 1.64$ & $5.78 \pm 2.75$ & $41.69 \pm 14.50$ & $10.76 \pm 1.83$ \\
\hline EP group & 55 & $30.40 \pm 2.87$ & $3.27 \pm 1.92$ & $22.14 \pm 1.93$ & $6.13 \pm 1.76$ & $5.15 \pm 2.04$ & $39.82 \pm 16.12$ & $11.21 \pm 1.67$ \\
\hline $\begin{array}{l}\text { Single early } \\
\text { SA group }\end{array}$ & 167 & $30.41 \pm 2.94$ & $3.55 \pm 2.45$ & $21.67 \pm 1.89$ & $6.63 \pm 2.44$ & $5.47 \pm 2.41$ & $41.44 \pm 17.72$ & $11.18 \pm 1.65$ \\
\hline BP group & 86 & $29.55 \pm 3.31$ & $3.79 \pm 2.08$ & $21.8 \pm 2.30$ & $6.49 \pm 2.22$ & $6.05 \pm 2.15$ & $44.70 \pm 10.00$ & $10.68 \pm 1.55$ \\
\hline$F$ & & 1.731 & 1.476 & 1.196 & 2.325 & 2.046 & 1.754 & 0.940 \\
\hline $\mathrm{P}$ & & 0.141 & 0.207 & 0.311 & 0.055 & 0.086 & 0.136 & 0.440 \\
\hline
\end{tabular}

bE2, basal estradiol; bFSH, basal follicle-stimulating hormone; bLH, basal luteinising hormone; BMI, body mass index; BP, biochemical pregnancy; EP, ectopic pregnancy; FET, frozen-thawed embryo transfer; OP, ongoing pregnancy; SA, spontaneous abortion. 


\begin{tabular}{|c|c|c|}
\hline Group & $\mathbf{n}$ & hCG ( $\left.\beta-\mathrm{hCG}_{7 \mathrm{~d}}\right)$ (range) \\
\hline Single OP group & 515 & 8.98 (5.93 to 14.09$)$ \\
\hline Twin OP group & 238 & $25.32(19.43 \text { to } 30.45)^{\star}$ \\
\hline EP group & 55 & $2.63(1.54 \text { to } 5.23)^{\star}$ \\
\hline Single early SA group & 167 & $4.34(2.60 \text { to } 7.35)^{\star}$ \\
\hline BP group & 86 & $2.92(1.62 \text { to } 4.48)^{\star}$ \\
\hline
\end{tabular}

${ }^{*} \mathrm{P}<0.01$ versus single OP group.

$\mathrm{BP}$, biochemical pregnancy; $\beta$-hCG, plasma human chorionic gonadotropin; EP, ectopic pregnancy; OP, ongoing pregnancy; $\mathrm{SA}$, spontaneous abortion.

(table 3; figure 2). At $\beta$-hCG $>17.95 \mathrm{IU} / \mathrm{L}$, the rates of twin OP, single OP and AP were $81.9 \%$ (195/238), $12.2 \%$ $(63 / 515)$ and $6.8 \%(21 / 308)$, respectively (table 4$)$.

Serum $\beta$-hCG levels were significantly higher in the normal pregnancy group compared with the BP, EP and single early SA groups $(\mathrm{p}<0.05)$ (table 2$)$. Serum $\beta$-hCG levels $\leq 5.34 \mathrm{U} / \mathrm{L}$ on the seventh day after FET predicted AP showing a moderate predictive value $(\mathrm{AUC}=0.843$, sensitivity $=71.43 \%$, specificity $=86.85 \%)$. Moreover, at $\beta$-hCG $\leq 5.34 \mathrm{IU} / \mathrm{L}$, the rates of single OP, twin OP and AP were $18.6 \%(96 / 515), 1.2 \%(3 / 238)$ and $71.4 \%$ $(220 / 308)$, respectively. Serum $\beta$-hCG levels $<4.34$ U/L, $4.53 \mathrm{U} / \mathrm{L}$ and $5.34 \mathrm{U} / \mathrm{L}$ were associated with a moderate probability of BP (AUC $=0.852$, sensitivity $=89.51 \%$, specificity $=75.58 \%), \quad \mathrm{EP} \quad(\mathrm{AUC}=0.860$, sensitivity $=72.73 \%$, specificity $=88.93 \%)$ and single early $\mathrm{SA} \quad(\mathrm{AUC}=0.738$, sensitivity $=63.47 \%$, specificity $=81.36 \%)$. However, an overlap in serum $\beta$-hCG levels was observed among the AP groups (table 3; figure 2). Furthermore, when 5.34 $\mathrm{IU} / \mathrm{L}<\beta-\mathrm{hCG} \leq 17.95 \mathrm{IU} / \mathrm{L}$, the rates of single $\mathrm{OP}$, twin OP and AP were $69.1 \%(356 / 515), 16.8 \%(40 / 238)$ and $24.7 \%$ (76/308), respectively (table 4 ).

\section{DISCUSSION}

The patients enrolled in our centre were routinely provided with 14 days of luteal support after FET. Our centre routinely measured hCG on the seventh day after transplantation. Reports from our clinical practices and previous research ${ }^{8}$ found that low serum hCG levels on the seventh day after ET were associated with poor pregnancy outcomes, which raises the following questions: Are hCG levels on day 7 after FET predictive of normal pregnancy outcomes or AP outcomes? If serum hCG levels are low on day 7 after FET, can increasing the dosages of oestrogen and progesterone improve pregnancy outcomes? For patients undergoing FET, if the serum hCG level is low 7 days after transplantation, can the drug be discontinued to alleviate the financial burden to the patient and discomfort to the buttocks caused by progesterone injection? To answer these questions, we conducted this retrospective analysis of previous cases.

A study Wang et $a l^{8}$ found that a serum $\beta$-hCG cutoff level of $2.5 \mathrm{mIU} / \mathrm{mL}$ on the seventh day after ET predicted pregnancy outcome and a serum $\beta$-hCG cut-off value of $10.8 \mathrm{mIU} / \mathrm{mL}$ predicted multiple pregnancies. We reported similar results; however, our study mainly focused on predicting the outcome of OP and AP. Serum $\beta$-hCG level was associated with pregnancy outcomes after FET. With an increase in serum $\beta$-hCG, the clinical continuous pregnancy rate increased, whereas the AP rates decreased.

Many studies have suggested that low serum $\beta$-hCG levels in early pregnancy are associated with AP outcomes. ${ }^{59}$ In our study, we observed an overlap of serum $\beta$-hCG levels among the AP groups; however, it was difficult to clearly distinguish between the single early SA, $\mathrm{EP}$, and BP groups. This study primarily aimed to investigate the difference in cut-off values between normal pregnancy outcomes and AP outcomes. A specific clinical significance was applied to predict normal and AP outcomes. Notably, it is suggested that a lower $\beta$-hCG level in early pregnancy often indicates a poor pregnancy outcome. In addition, dynamically assessing the $\beta$-hCG values, patient history and etiological characteristics are vital to effectively predict pregnancy outcomes. The number of nidated embryos affects the serum $\beta$-hCG level in early pregnancy because more than one gestational sac increases the serum $\beta$-hCG level. Patients with serum $\beta$-hCG $>17.95 \mathrm{IU} / \mathrm{L}$ and are older or have a history of the caesarean section should be alert to the possibility of twins. Therefore, doctors and patients should have psychological expectations as early as possible. Follow-up and ultrasound should be performed as soon as possible to take countermeasures to avoid adverse obstetric outcomes.

\begin{tabular}{|c|c|c|c|c|c|}
\hline Group & Cut-off (U/L) & AUC & $95 \% \mathrm{Cl}$ & Sensitivity (\%) & Specificity (\%) \\
\hline $\mathrm{BP}$ vs single $\mathrm{OP}$ & 4.34 & 0.852 & 0.821 to 0.888 & 89.51 & 75.58 \\
\hline Twin OP vs single OP & 17.95 & 0.903 & 0.880 to 0.923 & 81.93 & 87.77 \\
\hline EP vs single OP & 4.53 & 0.860 & 0.829 to 0.888 & 72.73 & 88.93 \\
\hline Single early $S A$ vs single $O P$ & 5.34 & 0.738 & 0.703 to 0.771 & 63.47 & 81.36 \\
\hline AP vs OP & 5.34 & 0.843 & 0.819 to 0.864 & 71.43 & 86.85 \\
\hline
\end{tabular}

AP, adverse pregnancy; AUC, area under the curve; BP, biochemical pregnancy; $\beta$-hCG, plasma human chorionic gonadotropin; EP, ectopic pregnancy; FET, frozen-thawed embryo transfer; OP, ongoing pregnancy; ROC, receiver operating characteristic; SA, spontaneous abortion. 

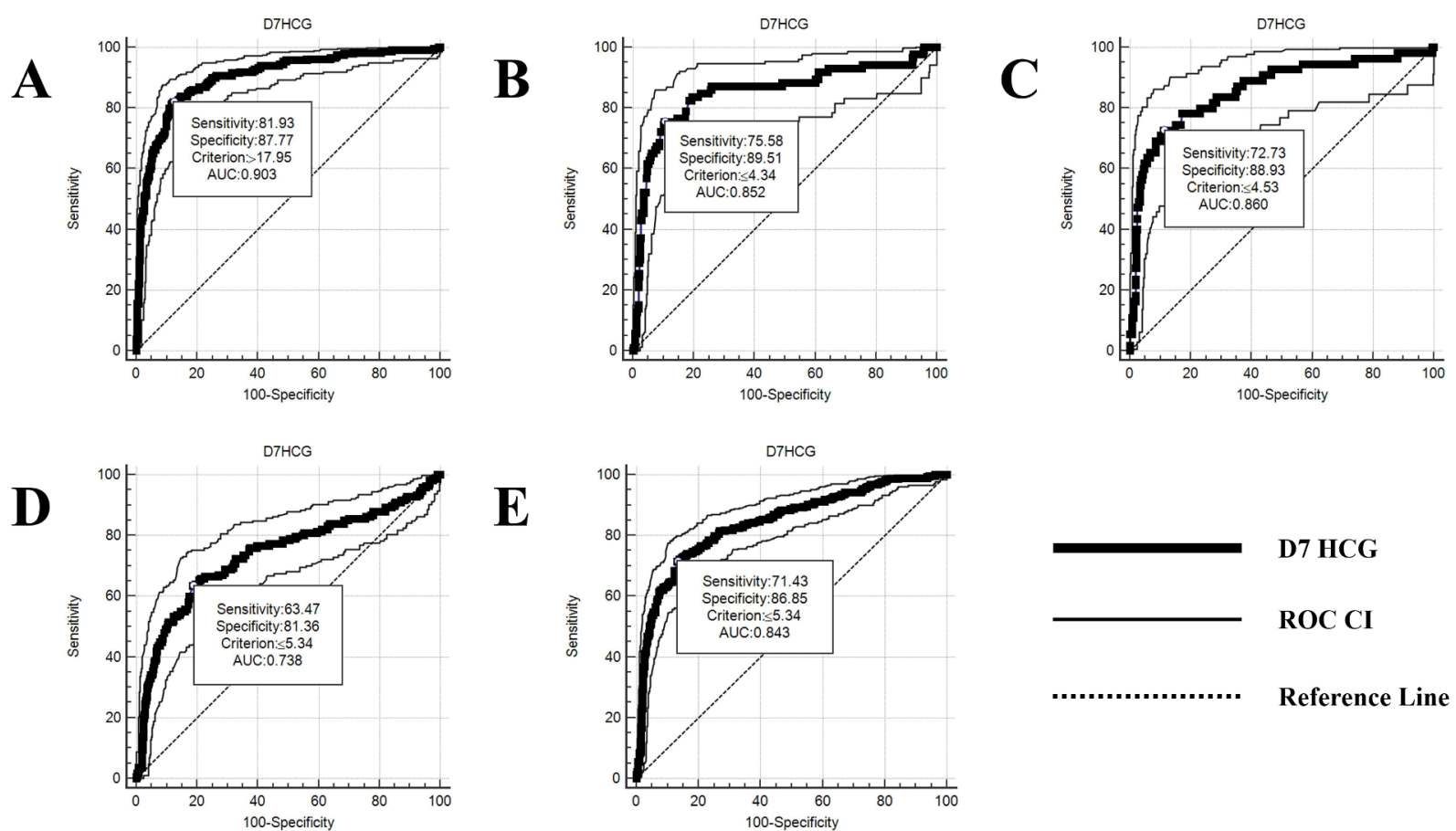

Figure 2 ROC curve for predicting the pregnancy outcome by serum $\beta$-hCG. The ROC curve was constructed by $100-$ specificity on the $x$-axis and sensitivity (\%) on the y-axis. (A) Prediction of twin and single OP with the ROC curve; (B) prediction of BP and single OP with the ROC curve; (C) prediction of EP and single OP with the ROC curve. (D) Prediction of single early SA and single OP with the ROC curve; (E) prediction of AP and single OP with the ROC curve. AP, adverse pregnancy; AUC, area under the curve; BP, biochemical pregnancy; $\beta$-hCG, plasma human chorionic gonadotropin; D7HCG, the serum $\beta$-hCG level on 7 days after frozen-thawed embryo transfer; EP, ectopic pregnancy; OP, ongoing pregnancy; ROC, receiver operating characteristic; SA, spontaneous abortion.

According to the results of this study, we raised the following questions: For patients undergoing FET, if the serum hCG level is low 7 days after transfer, can the drug be discontinued to alleviate the financial burden to the patient and discomfort to the buttocks caused by progesterone injection? Next, we plan to conduct a prospective study to answer these questions.

There were some limitations to this study. First, this was a retrospective study that is prone to selection bias. Second, a drug intervention may affect the initial serum $\beta$-hCG concentration during ART. Therefore, the clinical data of patients undergoing exogenous $\beta$-hCG for luteal support were excluded. Third, all the selected cycles were FET, fresh ET was not included. Fourth, the results only apply to patients with fallopian tube factor infertility. The effusion reflux of hydrosalpinx can also influence

Table 4 Composition ratio of different $\beta$-hCG levels in each group (N (\%))

\begin{tabular}{|c|c|c|c|c|}
\hline \multirow[b]{2}{*}{ Group } & \multirow[b]{2}{*}{$\mathbf{N}$} & \multicolumn{2}{|c|}{$\beta-\mathrm{hCG}(\mathrm{mlU} / \mathrm{mL})$} & \multirow{2}{*}{$\frac{N(\%)}{>>17.95}$} \\
\hline & & $\leq 5.34$ & $5.35-17.95$ & \\
\hline Single OP & 515 & 96 (18.6\%) & $356(69.1 \%)$ & $63(12.2 \%)$ \\
\hline Twin OP & 238 & $3(1.2 \%)$ & 40 (16.8\%) & 195 (81.9\%) \\
\hline AP & 308 & 220 (71.4\%) & 67 (21.8\%) & 21 (6.8\%) \\
\hline
\end{tabular}

AP, adverse pregnancy; $\beta$-hCG, plasma human chorionic gonadotropin; OP, ongoing pregnancy. the final pregnancy outcome, so we excluded such data, which may have slightly affected the pregnancy outcome. Last, some studies found that overweight, underweight, and older patients show increased early SA rates. ${ }^{10} 11$ Therefore, this patient cohort was limited to women with a BMI between 18.5 and 25 and aged $<38$ years.

In conclusion, serum $\beta$-hCG is vital in predicting early pregnancy outcomes value at $7 \mathrm{dpt}$. This is important for medical providers and patients as this indicator can guide future treatment plans and track patients with abnormal or high-risk pregnancies. However, because of differences in detection instruments, reagents, and methods used for the determination of $\beta$-hCG, there may be some differences among IVF studies in serum $\beta$-hCG values. Hence, the $\beta$-hCG cut-off levels reported in this study may not necessarily apply to other reproductive centres.

\section{Author affiliations}

${ }^{1}$ College of Traditional Chinese Medicine, Shandong University of Traditional Chinese Medicine, Jinan, China

${ }^{2}$ Integrative Medicine Research Centre of Reproduction and Heredity, Shandong University of Traditional Chinese Medicine Affiliated Hospital, Jinan, China

${ }^{3}$ The First Clinical College, Shandong University of traditional Chinese Medicine, Jinan, China

Acknowledgements Thanks to Xian-Ling Cao, Xiao Tian, Jian-Yun Zhao and Yang-Yang Yu for helping to collect data and give spiritual support. Thanks to all the patients for their agreement. Thank you very much!

Contributors LYuan, LYu, ZS and JS conceived and designed the experiments. LYuan, JS and JX analysed the data. LYuan, LYu, ZS, HJ and YS reviewed the 
literature. LYuan and LYu wrote the manuscript. Each of the authors has approved the final version of the manuscript, agree with this submission to 'BMJ Open'.

Funding The study was funded by National Natural Science Foundation, China (81874484).

Competing interests None declared.

Patient consent for publication Not required.

Ethics approval We received research ethics approval for this study from the Ethics Committee of the Center for Reproduction and Genetics, Affiliated Hospital of Shandong University of Traditional Chinese Medicine.

Provenance and peer review Not commissioned; externally peer reviewed.

Data availability statement Data are available in a public, open access repository. Extra data can be accessed via the Dryad data repository at https://datadryad.org/ with the doi:10.5061/dryad.8931zcrnj.

Open access This is an open access article distributed in accordance with the Creative Commons Attribution Non Commercial (CC BY-NC 4.0) license, which permits others to distribute, remix, adapt, build upon this work non-commercially, and license their derivative works on different terms, provided the original work is properly cited, appropriate credit is given, any changes made indicated, and the use is non-commercial. See: http://creativecommons.org/licenses/by-nc/4.0/.

\section{ORCID iD}

Zhengao Sun http://orcid.org/0000-0002-9723-1213

\section{REFERENCES}

1 Lawler CC, Budrys NM, Rodgers AK, et al. Serum beta human chorionic gonadotropin levels can inform outcome counseling after in vitro fertilization. Fertil Steril 2011;96:505-7.
2 Sung N, Kwak-Kim J, Koo HS, et al. Serum hCG- $\beta$ levels of postovulatory day 12 and 14 with the sequential application of hCG- $\beta$ fold change significantly increased predictability of pregnancy outcome after IVF-ET cycle. J Assist Reprod Genet 2016;33:1185-94.

$3 \mathrm{Kim} \mathrm{JH}$, Shin MS, Yi G, et al. Serum biomarkers for predicting pregnancy outcome in women undergoing IVF: human chorionic gonadotropin, progesterone, and inhibin a level at 11 days post-ET. Clin Exp Reprod Med 2012;39:28-32.

4 McCoy TW, Nakajima ST, Bohler HC. Age and a single day-14 betahCG can predict ongoing pregnancy following IVF. Reprod Biomed Online 2009;19:114-20.

5 Kahyaoğlu İnci, Demir B, Ertürk Aksakal S, et al. Value of posttransfer Day-12 beta human chorionic gonadotropin levels for pregnancy outcome prediction of intracytoplasmic sperm injection cycles. Balkan Med J 2017;34:450-7.

6 Naredi N, Singh SK, Sharma R. Does First Serum Beta-Human Chorionic Gonadotropin Value Prognosticate the Early Pregnancy Outcome in an In-Vitro Fertilisation Cycle? J Hum Reprod Sci 2017;10:108-13.

7 Løssl K, Oldenburg A, Toftager M, et al. Predictive value of plasma human chorionic gonadotropin measured 14 days after Day-2 single embryo transfer. Acta Obstet Gynecol Scand 2017;96:960-7.

8 Wang Q, Zhang R, Jia M, et al. Serum human chorionic gonadotropin measured 7 days following day 3 embryo transfer might predict pregnancy outcome in IVF. Gynecol Endocrinol 2017;33:62-6.

9 Urbancsek J, Hauzman E, Fedorcsák P, et al. Serum human chorionic gonadotropin measurements may predict pregnancy outcome and multiple gestation after in vitro fertilization. Fertil Steril 2002;78:540-2.

10 Song J, Chen SL, Sun L, et al. Analysis of embryo implantation and clinical pregnancy outcome in women of different ages. J Pract Med 2008;24:1539-41.

11 Veleva Z, Tiitinen A, Vilska S, et al. High and low BMI increase the risk of miscarriage after IVF/ICSI and FET. Hum Reprod 2008;23:878-84. 